\title{
Kırgız Türkçesinde Küçükbaş ve Büyükbaş Hayvanlara Yaşlarına Göre Verilen Adların Etimolojisi Üzerine Bir İnceleme
}

\section{A Study on the Etymology of the Naming of Ovine and Bovine According to Age in the Kirghiz Turkic Language}

\section{Kenjegul Kalieva ${ }^{1}$ (1)}

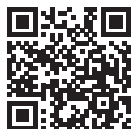

${ }^{1}$ Sivas Cumhuriyet Üniversitesi, Edebiyat Fakültesi, Çağdaş Türk Lehçeleri ve Edebiyatları Bölümü, Sivas, Türkiye

\section{ORCID: K.K. 0000-0001-8551-6759}

Sorumlu yazar/Corresponding author:

Kenjegul Kalieva,

Sivas Cumhuriyet Üniversitesi, Edebiyat Fakültesi, Çağdaș Türk Lehçeleri ve Edebiyatları Bölümü, Sivas, Türkiye

E-mail: kenjegul.kalieva@yahoo.com

Başvuru/Submitted: 29.05.2020

Revizyon Talebi/Revision Requested: 11.09.2020 Son Revizyon/Last Revision Received: 11.09.2020 Kabul/Accepted: 23.09 .2020

\section{Atıf/Citation:}

Kalieva, K. (2020). Kırgız Türkçesinde küçükbaş ve büyükbaş hayvanlara yaşlarına göre verilen adların etimolojisi üzerine bir inceleme. TUDED $60(2), 609-627$

https://doi.org/10.26650/TUDED2020-0008

\section{ÖZET}

Hayvancılık geleneği günümüzde Kırgızlarda devam etmektedir. Bu gelenek, Kırgızlar için hem gelir kaynağını hem de hayvancılık kültürünün devam ettirilmesini beraberinde getirmiştir. Kırgızlar küçükbaş ve büyükbaş hayvanları yaşlarına göre adlandırırlar. Bu adlandırma hayvanın fiziksel yapısına, diş sayısına, dişi veya erkek olmasına bağlıdır. Bu çalışmada küçükbaş hayvan olarak koyun, büyükbaş hayvan olarak inek ve at (cllkı) ele alınmaktadır. Kırgız Türkçesinin ağızlarında hayvanların yaşlarına göre verilen adlar aynı değildir, bu da hayvancıllı̆ın Kırgızistan'ın her yerinde aynı şekilde gelişmediğini ve Kırgızların komşu halklarla olan kültürel ilişkilerini göstermektedir.

Bu çalışmada Kırgız Türkçesinde küçükbaş ve büyükbaş hayvanların yaşlarına göre adlandırmaları ve bu adlandırmalar etimolojik yönden incelenecektir. Bunun yanı sıra adlandırmalar coğrafi bakımdan komşu olan Kıpçak grubundan Kazak Türkçesiyle ve Güney Doğu Türk dilleriyle (Yeni Uygur ve Özbek) ve Oğuz grubundan Türkiye Türkçesiyle karşılaştırılacaktır. Çalıșmaya, Türkiye Türkçesinin dâhil edilmesinin nedeni Türkiye'de hayvancılık geleneğinin azalmasının sonucu olarak hayvanlarla ilgili adlandırmalarda değişimleri tespit etmektir. Bu çalışmanın yapılmasının önemli olan bir diğer sebebi de, Türk dünyasının yeni neslinin eski Türk hayvancılık geleneğini ve gelenekle ilgili terimlerini unutmaya başlamasıdır. $\mathrm{Bu}$ amaçla, Türkiye'de hayvancılıkla uğraşan çobanların bilgilerine başvurulmuş ve elde edilen veriler Derleme Sözlüğü'yle ve etimoloji sözlükleriyle karşılaştırılmıştır.

Anahtar Kelimeler: Hayvan Adlandırmaları, Kazak Türkçesi, Güneydoğu Türk Dilleri (Özbekçe ve Yeni Uygurca), Türkiye Türkçesi, Moğolca

\section{ABSTRACT}

Animal husbandary is one of the traditional foundations of the economy and culture of the Kirghiz people and it still plays an important part in their lives today Kirghiz people name younger and older cattle differently according to their age. This nomenclature depends on the gender of the animal, whether it is female or male. The names of cattle by age may not be the same in all the various parts of Kirghizstan, which suggests that animal husbandry has not developed in the same way throughout Kirghizstan and that, at the same time, Kirghiz people have close ties with their neighbouring countries.

This article presents the naming of cattle according to age and it will also offer etymological explanations of the names. The naming of cattle by age will be compared with practices in geographically neighboring Turkic Language areas: the Kazak Turkic language and the Southeast Turkic languages (New Uyghur and Özbek). However, the names will also be compared with Turkish due to the decrease in livestock husbandary in Turkey. The data used in this article, are based on materials provided by shepherds in Turkey. Different etymological dictionaries have also been evaluated in this study. Keywords: Age naming, ovine and bovine animals, Kazak Turkic Language, Southeast Turkic Languages, Türkish, Mongolian 


\section{EXTENDED ABSTRACT}

Livestock husbandary is one of the traditional foundations of the economy and culture of the Kirghiz people and still takes an important place in their lives. The development of livestock practice is different in the northern and southern regions of Kirghizstan. The reason for this difference is primarily based on differences in geography and climate, as well as the impact of neighboring cultures on Kirghizstan. Nowadays, livestock husbandry is typically well developed in North Kirghizstan. There are high mountains and wide plateaus in North Kirghizstan and it is suitable for developing husbandry. In South Kirghizstan animal husbandry is less developed because of the hot climate and the fields and wide areas are more suitable for agriculture. In Kirghizstan the animals are classified as ovine and bovine. Bovine animals: at "mare or horse", uy “cow”, topoz "buffalo". Ovine animals: kozu 'lamb', koy 'sheep', koçkor 'ram' or ečki 'goat'. Another important factor in livestock husbandary in Kirghizstan is the naming of animals according to age. The ages of animals are generally determined by their physical structure, number of teeth, and gender (female or male). This article presents the naming by age of ovine and bovine animals and it also offers etymological explanations. The naming by age of cattle will be compared with the practices in geographically neighboring Turkic Languages: namely, the Kazak Turkic language and Southeast Turkic languages (New Uyghur and Özbek). However, the names will also be compared with Turkish due to the decrease in livestock husbundary in Turkey. The data used in this article are based on information provided by shepherds in Kirghizstan and Turkey as well as on different etymological dictionaries and articles. Some grammar books have also evaluated. The paper is structured as follows: Section one presents general information about livestock husbandary. Section two concerns the naming by age of ovine animals (sheep) and section three discusses the naming by age of bovine animals (cow, horse). Section four summarizes the results.

\section{Ovine animals (sheep)}

- "Sheep": koy (KirgTur., KazTur., ÖzbTur., N.UygTur); koyun (TTur).

- "Newborn lamb”: kozu (KirgTur), kozı (KazTur), kuzi (ÖzbTur), koza (N.UygTur), kuzu (TTur).

- "One and two year old female lamb who has not given birth": toktu (in North Kirghizstan and in some regions in South Kirghizstan; toktı (KazTur), tohlu (ÖzbTur), tohli (N.UygTur), toklu (TTur)). Cusak (in South Kirghizstan).

- "One and two year old male lamb": boruk (KirgTur.), şişek (in South Kirghizstan, TTur.); şişak (ÖzbTur); makak (in some dialects of Turkish).

- "Three year old female lamb": kunan koy (in some dialects of Kirghiz Turkic), sooluk (in Chuy region); sağllk (N.Uyg).

- "Three year old castrated male lamb": irik (in North dialects of Kirghiz Turkic).

- "Four year old female and male sheep": dönön (in South dialects of Kirghiz Turkic; KazTur., ÖzbTur., N.UygTur), tögörök (in North dialects of Kirghiz Turkic), çarı koy (in the dialects of Kirghiz Turkic in Fergana Valley). 
- "Five and six year old sheep": mama /subay koy (in North dialects of Kirghiz Turkic), panc / şaş koy (in some dialects of Kirghiz Turkic in Fergana Valley).

\section{Bovine animals (cow and horse)}

The following terms for naming by age of bovine animals were determined in the dialects of Kirghiz Turkic.

a. "cow"

- “Newborn calf”: muzoo (in North Kirghizstan), torpok (in some dialects of South Kirghizstan); buzav (KazTur.), buzak (ÖzbTur), topak (N.UygTur), buzağı (TTur.).

- "A calf in its first year (from 6 months)": torpok (in North and South Kirghizstan); torpak (KazTur.), topak (N.UygTur). The terms körpe "six month old female and male calf" and yaşar "one year old female and male calf" were determined in some villages near the province of Sivas.

- "A calf in its second year": kunan torpok (in North Kirghizstan and also in some dialects of South Kirghizstan). Tana (in Kirghiz dialects in Kazakhstan), KazTur., ÖzbTur., N.UygTur. In Turkish two terms are used: düve "two year old female calf"; dana "two year old male calf".

- “Three year old calf which has not given birth': kunacın (KirgTur., KazTur), gunucu (N.UygTur).

- "Cow": uy (in North and South Kirghizstan), slyır (in some dialects of Kirghiz Turkic in the Fergana Valley), KazTur., sigir (ÖzbTur), kala (N.UygTur.); inek (TTur).

- "Bull”: buka (KirgTur., KazTur., ÖzbTurk), boga (N.UygTur., TTur).

- "Four year old castrated bull”: noopas (in South Kirghizstan); novvos (ÖzbTur).

- “Castrated bull”: ögüz (KirgTur), ögiz (KazTur); hökiz (ÖzbTur), höküz (N.UzgTur); öküz (TTur).

\section{b. "Horse"}

- "Newborn foal": kulun (KirgTur., ÖzbTur., TTur), kulın (KazTur), ġulun (N.UygTur).

- "One year old foal”: tay (KirgTur., KazTur., TTur), toy (ÖzbTur), tayçak (N.UzgTur).

- “Three year old foal”: kunan (KirgTur., KazTur), gunan (N.UygTur), kulan (in some dialects of Turkish).

- "Mare which has not given birth": baytal (KirgTur., KazTur., ÖzbTur., N.UygTur).

- "Mare": bee (KirgTur), biye (KazTur), biya (ÖzbTur).

- "Stallion": aygır (KirgTur., KazTur., ÖzbTur., N.UygTur., TTur).

- "A castrated stallion; horse": at (KirgTur., KazTur., ÖzbTur., N.UygTur., TTur).

- "The term asly which is used for a horse up to five years of age": asly (KirgTur), ası (KazTur). 


\section{GíRIŞ}

Asırlar boyu hayvancılık geleneği Kırgızlarda önemli bir yer tutmaktadır. Kırgızlar için hayvancılık hem bir geçim kaynağı hem de kültürün bir parçası olmuştur. Hayvancılık geleneğinin gelişimi Kırgızistan’ın kuzey ve güney bölgelerinde farklılık yaratmaktadır. Bu farklılığın sebebi öncelikle Kırgızistan'ın coğrafyasına, iklimine ve komşu kültürlerin etkisine dayanmaktadır. Günümüzde hayvancılık geleneği genellikle Kırgızistan’ın güneyine göre kuzeyinde iyi gelişmiştir, çünkü Kırgızistan’ın kuzeyindeki yüksek dağlar ve geniş yaylalar ve iklim hayvancılığın gelişmesi için son derece uygundur. Kırgızistan'ın güneyinde ise hem iklimin sıcak olması hem de yerli halkın tarıma yönelmesi hayvancılığın bu bölgede gerilemesine neden olmuştur. Kırgızistan' da hayvancılık geleneğinde hayvanlar, küçükbaş ve büyükbaş olarak sınıflandırılmaktadır. Büyükbaş hayvanlar: cılkl 'kısrak veya at sürüsü', uy 'inek', topoz 'manda, yak'; Küçükbaş hayvanlar kozu 'kuzu', koy 'koyun', koçkor 'koç' veya $e c ̧ k i$ 'keçi'. Bölgedeki hayvancılık geleneğinin önemli bir unsuru da hayvanların yaşlarına göre adlandırılmasıdır. Hayvanların yaşları genellikle fiziksel yapısına, diş sayısına, dişil veya eril olmasına göre belirlenir. Şimdiye kadar çalışılan ağız derlemelerinde hayvanların yaşlarına göre verilen adlarda farklılıklar olduğu tespit edilmektedir. Bu farklılığın sebepleri arasına hayvancılık geleneğinin gelişim süreci, komşu dillerin etkisi, Moğolcadan veya Farsça-Arapçadan ödünç alınan sözcüklerin Kırgız Türkçesinin ağılarında aynı şekilde veya anlamda kullanılmaması gösterilebilir. Bu makalede, Kırgız Türkçesinde küçükbaş ve büyükbaş hayvanların yaşlarına göre nasıl adlandırıldığı, Kırgız Türkçesinin ağızlarında bu adlandırmaların olup olmadığı tespit edilerek coğrafi bakımdan komşu Türk dilleriyle Kazak, Özbek ve Yeni Uygur Türkçeleriyle ve Türkiye Türkçesiyle karşılaştırılmıştır. Makalede ele alınan sözcükler için Yudahin'in sözlüğü, Kırgız Türkçesindeki ağız çalışmaları taranmıştır. Bunun yanı sıra küçükbaş ve büyükbaş hayvanların yaşlarına göre adlandırılmasıyla ilgili bilgiler hâlihazırda hayvancılıkla uğraşan çobanlardan ${ }^{1}$ alınmıştır.

\section{KÜÇÜKBAŞ VE BÜYÜKBAŞ HAYVANLARININ YAŞLARINA GÖRE ADLANDIRILMASI}

\section{Küçükbaş Hayvan (Koyun)}

1.1. koy: Yudahin I. 392. Rus. Овца (общее название) "koyun: genel bir adlandırma”. Kırgız Türkçesinin bütün ağızlarında bulunmaktadır. Bu sözcük Eski Türkçeden başlayarak günümüz Çağdaş Türk dillerinde de kullanılmaktadır: Clauson 631a ko: ̌̆; KazTS 169, ÖzbRS 634, Y.UygTS 246 koy, TTür. 254 koyun. Oğuz grubundaki Türk dillerinde (Türkiye Türkçesi, Azerbaycan ve Türkmen Türkçelerinde) koyun ve diğer Türk dillerinde koy olarak kullanıldığı görülmektedir. Eski Türkçede ko:দ̆ biçiminin sonundaki -ń- sesi Türk dillerine $-y$ - olarak geçmiştir. Eren'e (254b) göre Türkiye Türkçesindeki koyun sözcüğü -(u)n küçültme ekiyle yapılmıştır.

1 Bilgilerini bizimle paylaşan Seydılda Osmanakunov’a, Avazbek Osmanakunov’a, Aman Satarov’a, Kanat Kutbidinov'a; TTürk. İrfan Türkmen'e, Mehmet Akbaş'a, Hasan Aydın'a, Celal Gezer'e teşekkürlerimizi sunuyoruz. 
1.2 kozu: Yudahin I. 392 Rus. ягненок (домашний и дикий) “уeni doğmuş koyun yavrusu: evcil ve yabani”. Kırgız Türkçesinin bütün ağızlarında bulunmaktadır. Eski Türkçeden beri kullanılan kuzi (Clauson 681a) sözcügüu, bütün Türk dillerine bazı ses değişikliğine uğrayarak geçer: KazTS 169 kozl, ÖzbRS 634 kuzi, Y.UygTS 246 koza, TTür. kuzu.

Sözcüğün etimolojisiyle ilgili farklı görüşler vardır. Seydakmatov 148 kozu sözcüğünün ET'de kodkı "mütevazı; mütevazı insan" (Clauson 599b) sözcüğünden ikinci hece başındaki - $k$ - sesinin düşmesi ile türediğini düşünmektedir, bir diğer açıklamasında da kozunun "mülayim, yardıma muhtaç” bir hayvancık olduğundan dolayı kuzu sözcüğünün ET'deki kodkı sözcüğünden türediğini öne sürmüştür. Eski Türkçeden Moğolcaya kurga (Lessing 987a) şeklinde geçtiği düşünülmektedir (Ayrıntılı bk. Doerfer TMEN 304, Räsänen 285a, Eren, 272b).

1.3. toktu I: Yudahin II. 245 Rus. ярка “kuzulamamış dişi kuzu”. toktu sözcüğünün Kırgız Türkçesinin ses uyumuna göre biçimlendiği görülmektedir Hem toktu hem de cusak "kuzulamamış dişi kuzu” olarak Calal-Abad ağızında kullanılmaktadır (kş. Bakinova \& Konduchalova, 1958: 107). Kırgızistan'ın kuzey bölgesinde kuzulamamış dişi kuzuya toktu denilirken, Kırgızistan’ın güney bölgesinde erkek kuzuya toktu adı verilir. Komşu Türk dillerinde toktu sözcüğü şu şekilde bilinmektedir: KazTS 273 toktı "altı aydan bir yaşına kadar olan kuzu”, Y.UygTS 416 tohlu, ÖzbRS 468 tohli ancak hem Yeni Uygur Türkçesinde hem de Özbek Türkçesinde kuzunun yaşı ve cinsiyeti belirtilmemiştir.

Türkiye'de hâlihazırda hayvancılıkla uğraşan Mehmet Akbaş’a (Samsun, Bafra İlçesi Şeyhören Köyü), İrfan Türkmen'e (İskilip /Çorum, Hallı Köyü), Hasan Aydın'a (Sivas, Yıldız Beldesi), Celal Gezer'e (Manisa, Akhisar İlçesi Arabacıbozköy Köyü) sorulduğunda toklu sözcügünün sadece anlam farklılığı olduğu görülmektedir. Karadeniz tarafında toklu erkek kuzulara denilirken, İç Anadolu'da ise altı veya yedi aylık hem dişi hem de erkek kuzunun toklu olarak adlandırıldığı tespit edilmiştir. Ancak Batı Ege tarafında hiç yavrulamamış dişi kuzuya toklu adı verilir. Eren'de (410a) toklu "altı aylıktan bir yaşına kadar olan erkek kuzu"; DS (V, 3950a/b) toklu "hem dişi hem de erkek bir yaşında kuzu".

Toktu sözcüğünün etimolojisine bakıldığında Türkçe bir kelime olduğu görülmektedir. DLT'de (186) toklı “altı aylık kuzu” olarak geçmektedir, ancak dişi veya erkek olduğu bilinmemektedir. Clauson'da (469a) toqlı "birkaç aylık kuzu; kuzudan biraz büyük ancak koyundan küçük” biçiminde yer almaktadır. Kâşgarlı-Mahmud, toq-luk sözcügünün toq "saçsızlık; boynuzsuzluk" -luk ekiyle türediğini ifade etmektedir. Tok sözcüğü "saçı olmayan; kel" anlamıyla Eski Türkçede bilinmektedir: Clauson 464b; DLT 144 "boynuzsuz; boynuzu olmayan hayvan". Eren, Rus dilinin ağızlarında toxtuy sözcügü "boynuzları çıkmaya başlayan burulmuş koç" anlamıyla görüldüğünü belirtmiş (Ayrıntılı bk. Eren 410a; Doerfer TMEN 909, Räsänen 485b).

1.4. boruk: Yudahin I. 147 Rus. двухлетний валух “iki yaşındaki erkek kuzu”. Bu sözcük Kırgız Türkçesinin ağızlarında da geçer ancak anlam bakımından farklılık göstermektedir. Kırgızistan’ın kuzeyinde (Çüy, Isık-Köl, Narın Bölgeleri) boruk sözcüğü “'bir yaşını doldurmamış 
erkek kuzu veya bahar ayında doğmuş erkek kuzuların koç olma özelliğine sahip olmayan, beşinci ayına doğru iğdiş edilmiş" anlamındadır. Enenmiş beş altı aylık kuzular da boruk olarak adlandırılır. Güney Kırgızistan'da ise bir yaşına girmemiş erkek kuzular toktu, şişek veya cusak (bk. toqtu, şişek, cusak) olarak adlandırılır. Boruk sözcüğü, komşu Türk dillerinde bulunmamaktadır. Celal Gezer'in (Manisa, Akhisar) verdiği bilgiye göre erkek kuzuya makak da denmektedir. Türkiye Türkçesi Sözlüğü’ne (TTürS.1609) bakıldığında makak sözcüğü ‘fr. Macaque hay "Güneydoğu Asya' da yaşayan kuyruklu bir maymun” anlamıla görülmektedir. Eren makak sözcüğüyle ilgili bilgi vermemiştir; DS (IV, 3107b) makak III. "tavşan yavrusu”. Makak sözcügüü (< $\mathrm{ar}^{2}$. sütten kesilmiş koyun) Arapçadan ödünçleme olmalıdır; ancak anlam değişikliğine uğrayarak erkek kuzu makak olarak adlandırılmış olabilir.

Kırgız Türkçesinin etimolojik sözlüğüne bakıldığında boruk sözcüğüyle ilgili pek az bilgiye ulaşılmaktadır. Yudahin sözlüğünde boruk sözcüğünün etimolojisi ile ilgili bilgi vermemektedir. Seydakmatov (1988: 60, 61) etimolojik sözlüğünde boruk sözcüğünün “enenmiş kuzu” anlamına geldiğini, bor- fiilinden türediğini savunmuştur. Bunun yanı sıra Seydakmatov, Şçerbak’ın (1961: 111) Nogay Türkçesindeki burak sözcügüüle ilgili etimolojik açıklamasını desteklemiştir. Şçerbak'a göre burak sözcüğü bur-, bitte-, bıç- “enemek, kısırlaştırmak” fillerinden türemiştir. Fiilin anlamına bakılırsa bur- "döndürmek" ve erkek kuzunun koç olmasından döndürmek veya kesmek manasını verebilir. Bu sözcüğün iki farklı etimolojisi düşünülebilir.

a. Kırgız Türkçesinde börk / börük sözcükleri “kürkten yapılmış şapka türü” bulunmaktadır (Yudahin I. 152: börk/börük "şapka / tebetey”). Eski Türkçe'de börk "şapka“" anlamı ile karşımıza çıkmaktadır (Clauson 362a). Dıykanov (1980: 88) börk/börük sözcüklerin Moğolcadan alıntı olduğunu belirtmiştir. Günümüz Kırgız Türkçesinde bu sözcük kullanılmamaktadır. Ancak Manas destanında tespit edilen börk biçimi arkaik bir sözcük olduğunu düşündürmektedir. Sözcük Manas destanında karşımıza çıkmaktadır, demek ki arkaik bir sözcüktür. Börk / börük (şapka) kuzu kürkünden yapıldığı için kuzuya da boruk ismi verilmiş olabilir. Bu durumda börk / börük biçimleri ses değişimine uğramıştır, ö/o, ü/u.

b. Bu sözcük alıntı bir kelime de olabilir. Moğolca-Rusça sözlüğüne (MoğRS 78) bakıldığında borlon sözcüğünün "bir yaşındaki oğlak” anlamı ile karşılaşılmaktadır. Önemli bir diğer husus da Kalmukçada (KalmRS 111) borlık II sözcüğü "bir yaşına girmemiş yavru” anlamı geçmektedir. Borlık sözcüğü Kırgızcanın ses uyumuna göre boruk biçimi almış olabilir.

1.5. cusak: Yudahin I 270 cusak I GK “genç keçi”. Kazakistan’ da yaşayan Kırgızlarda ise cusak "iki yaşındaki koyun yavrusu” anlamına gelmektedir (kş. Beysekeev, 1964: 61). Tiyanşan bölgesindeki Kırgızlarda ise bir yaşındaki daha kuzulamamış koyuna cusak denilmektedir ancak Yudahin, Tiyanşan Bölgesi’nin hangi illeri, ilçeleri kapsadığını belirtmemiş çünkü cusak sözcügü Narın, Isık-Köl, At-Başı taraflarında bilinmemektedir. Hem komşu Türk dillerinde hem de Türkiye Türkçesinde bu sözcük bulunamamıştır.

2 https://www.almaany.com/ur/dict/ar-ur/s\%C3\%BCten-kesilen-koyun $\% \mathrm{C} 3 \% \mathrm{BCrk} \% \mathrm{C} 3 \% \mathrm{~A} 7 \mathrm{e}-$ $\mathrm{s} \% \mathrm{C} 3 \% \mathrm{~B} 6 \mathrm{zl} \% \mathrm{C} 3 \% \mathrm{BCk} / \mathrm{c}=\mathrm{t} \% \mathrm{C} 3 \% \mathrm{BCm}$ 
Kırgız Türkçesinin etimolojik sözlüklerinde de sözcükle ilgili herhangi bir bilgiye rastlanmamaktadır. Cusak sözcüğü yazo- / yaza- (> coza-k / cusa-k) fillerinden türemiş olabilir çünkü Eski Türkçede (DLT 983; Clauson 985a) yazo- fiili “koyun vb. kısırlaşmış, çiftleştiği halde gebe kalmamak; dişi koyun kısırdı” anlamı ile görülmektedir. Eski Türkçede hece başındaki $y$ - sesi Kırgız Türkçesinde genellikle $c$ - olur. Sözcüğü anlam bakımından ele aldığımızda Eski Türkçedeki anlamının değişerek Kırgız Türkçesinde "kısır olmayıp, ancak daha doğurmamış iki yaşındaki koyun" anlamına geldiği söylenebilir.

1.6. şişek /işek: Yudahin II 410 “iki yaşındaki koyun”. Kırgız Türkçesinin Calal-Abad ve Batken ağızlarında “iki yaşındaki erkek koyun” (kş. Bakinova \& Konduchalova, 1958: 108; Batken Ağızı Derlemelerden). Kırgızistan'ın güneyinde koçkorok diye de adlandırılır. Özbekistan'daki Kırgızlarda şişek "iki yaşındaki koyun” (kş. Abduldaev \& Bakinova, 1962: 159). Kırgız Türkçesinin Çüy ağzında iki veya üç dişi olan koyunlara da bu ad verilir (kş. Bakinova, 1959: 78). Şişek sözcüğü Narın, Isık-Köl, At-Başı taraflarında bilinmemektedir. Bu sözcük Fergana bölgesinde daha yaygındır: ÖzbRS 543 şişak. Kazak ve Yeni Uygur Türkçelerinde bu sözcük bilinmemektedir. Karadeniz ve Batı Ege tarafinda şişek "altı veya yedi aylık doğurmamış kuzuya" denilirken, İç Anadolu'da iki yaşına girmiş hiç yavrulamamış bütün hayvanlara denildiği görülmektedir; DS (V, 3788a/b) şişek "hem erkek hem dişi koyun".

Sözcüğün etimolojisine bakıldığında, sözcük Türkçe kökenli olup gerileyici benzeşmeye uğramıştır şişak/şişek < tişek < tişe - "diş çıkarmak" -k: DLT'de 167 tişek "iki yaşındaki koyun" sözcük anlamı ile geçmektedir. Seydakmatov da şişek sözcügünün tişek sözcüğünden türediğini düşünmektedir (kş. Seydakmatov, 1988: 259). Eren, şişek sözcüğünün etimolojisinin bazı dilciler (Räsänen, Şçerbak, Clauson) tarafından yanlış yorumlandığını belirtmiştir (ayrıntılı bk. Eren, 1999: 389, 390). Kırgızistan'ın kuzeyinde ise şişeğin karş1lığ 1 toktudur.

1.7. Üç yaşındaki koyun: Kırgız Türkçesinin ağızlarında iki yaşından sonra koyunlar dişlerinin sayısına göre farklı adlarla adlandırmaktadır: Cala-Abad ağızı: kunan koy (bk. kunan), Çüy ağızı: sooluk "üc yaşında koyun” (kş. Bakinova \& Konduchalova 1958:107; Bakinova, 1959: 78). Yeni Uygur Türkçesinde să̆llk "yavrusu olan dişi koyun" (Y.UygTS 337) olarak geçmektedir.

Çüy ağzında görünen sooluk sözcüğüyle Yeni Uygur Türkçesindeki sağlık aynı kökten gelmektedir. Clauson (809a), sağlık sözcüğünün süt veren hayvan anlamına gelerek sadece Güney Doğu Türk dillerinde korunduğunu ve diğer Türk dillerinde sağın biçiminin kullanıldığını belirtmiştir. Ancak Azerbaycan ve Türkiye Türkçelerinde să̆mal şeklinde olduğunu ifade etmiştir. Eren (349b), sağmal "süt veren, sağılan" anlamını vererek Türkçe bir sözcük olduğunu düşünmüştür, çünkü Ramstedt (KWb 317) ve Şçerbak (İRL TJa 112) sağmal Moğolcadan ödünçleme bir sözcük olduğunu öne sürmüşlerdir. Ancak Eren Kırgız Türkçesinde - mal ekinin olduğunu ve bu ekten türeyen sözcükleri (kösömöl, tanımal) örnek olarak vermiştir (bk. Eren, 1999: 349) ve Ramstedt ile Şçerbak’ın açıklamalarının tartışılması gerektiğini belirtmiştir. Bu durumda Kırgız Türkçesinde geçen sooluk, saamal ve saan sözcüklerini tekrardan gözden 
geçirebiliriz. Yudahin'in sözlüğünde, (155) sooluk II “beş yaşındaki koyun”; hangi ağızlarda kullanıldığını belirtmemiş, (119) saamal "daha kımız olmamış süt”, (119) saan "süt veren hayvan”. Seydakmatov (205), sooluk koy tamlamasına "kuzulu koyuna” ancak saan sözcüğüyle ilgili herhangi bir bilgi verilmemiştir. Kırgız Türkçesindeki saan sözcüğü ET’de sağın biçiminden türemiş olabilir: saa- $n<s a w-\imath n<s a \breve{g}$-ın. Sooluk sözcüğünün Moğolca saal "süt veren hayvan" (Lessing 657) köküne bağlı olduğunu ancak Kırgız Türkçesindeki saamal sözcüğünün kökünün Türkiye Türkçesindeki să̆mal sözcügüule bağlantılı olmadığını düşünmekteyim.

1.8. Irik: Yudahin I. 303 Rus. трех летний валух “üç yaşındaki erkek koç”. Kırgızistan’ın güney bölgesindeki ağızlarda bu sözcük bilinmemektedir. Sözcük daha çok Kırgızistan’ın kuzey ağızlarında, özellikle Isık-Köl ve Narın'da görülmektedir. Şimdiye kadar yapılan ağız çalışmalarında da bu sözcüğe rastlanmamaktadır. Batken ağzında pıçma (< bıç-ma) “enenmiş koç" anlamı ile bilinmektedir. Kazak ve Özbek Türkçelerinde bu sözcük bilinmemektedir. Türkiye Türkçesinde ise erkeç sözcügü (ağızlarda irkeç) “erkek keçi” anlamıyla bilinmektedir; DS II, 1773b erkeç “üç dört yaşlarında olan enenmiş keçi”. Eren, erkeç sözcüğünün irik sözcüğüyle aynı kökten olduğunu dile getirmiştir: irk + (e)ç küçültme eki. Eski Kıpçakçada erkeç sözcügünün hem "enenmiş keçiyi“" hem de "enenmiş koçu” adlandırdığını da belirtmiştir (bk. Eren 137b). Räsänen (173b), irk sözcüğünün Yeni Uygurcada eriq koyun anlamıyla bilindiğini ifade etmektedir. Bununla birlikte Räsänen'e göre irik sözcüğü Balkarcada, Koybalicede, Sagaycada ve Teleütçede "koyun” olarak geçmektedir ve Türkmencede ürü biçimi "enenmiş koç" anlamıyla bilinmektedir. Eski Uygurcanın din dişı metinlerinde de irkeç "teke, erkek keçi” anlamıyla bilinmektedir (bk. Ayazlı, 2016: 127).

Sözcüğün etimolojisiyle ilgili Seydakmatov (218), irik sözcügüün̈ “üç yaşındaki büyük erkek koyun" anlamına geldiğini ifade etmiş ve bu yaştaki koyunun kemikleri büyüyüp kendisi de olgun bir çağa geldiği için sözcüğü iri "büyük" köküne bağlamıştır. (Clauson 220b): irk "üç yaşındaki koç”; (DLT 20) "dört yaşına girmiş koyun”; (Lessing 414a) irek "enenmiş koç”. Eren (137b) Kırgız Türkçesindeki erkeç “enenmiş keçi” ile irik “enenmiş koç” sözcüklerinin aynı köke bağlı olduğunu düşünmüşsür. Ancak sözcüklerin köklerine ve eklerine bakılarak iki farklı şekilde olduğu düşünülebilir ve Kırgız Türkçesindeki irik sözcügüunün etimolojisi iki şekilde yorumlanabilir:

a. Kırgız Türkçesinde küçükbaş ve büyükbaş hayvanların erkeklerini enemek fiili için bitte-, (Yudahin I 137) bıç- (Yudahin I 173), ırk kıl- (Yudahin II 304) sözcükleri kullanılmaktadır. Irk kıl- fiili yaygın kullanılan bir fiil değildir ancak irik "enenmiş üç yaşındaki koç” sözcüğü bu fiilden türemiş olabilir: irik $<i r k-k$;

b. Moğolcadan (irek > irik) ödünçleme bir sözcük de olabilir. Kırgız Türkçesinde “enenmiş keçi” için hem serke (Yudahin II 146) hem de erkeç (Yudahin II 463) sözcükleri kullanılmaktadır ancak her iki sözcüğün de irik sözcüğüyle aynı kökten olabileceği tartışılmalıdır.

1.9. Dört yaşındaki koyun: Kırgız Türkçesinde dört dişi olan koyunlara tögörök/dönön adı verilir. Ancak dönön sözcüğü Kırgız Türkçesinin ağızlarında anlam bakımından değişmiştir. 
Kazakistan'da yaşayan Kırgızlarda dört yaşında olan bütün hayvanlara dönön adı verilirken, Çatkal, Calal-Abad illerinde dört veya beş dişi olan koyunlara dönön adı verilmektedir. İçkilik ağızlarında dört dişi olan koyunlara dönön adı verilirken, Batken ağzında çaar, Çüy bölgesinde ise altı yaşındaki koyuna dönön denmektedir. Ancak dönön sözcüğü Isık-Köl, Narın, At-Başı taraflarında pek bilinmemektedir (bk. Kazakistan'daki Kırgızlar Beyşekeev, 1964: 60; Çatkal ve Cala-Abad Ağızları Abduldaev, Bakinova, Konduchalova, 1958: 107; Bakinova \& Sıdıkov 1958: 107; İçkilik Ağızları Bakinova, 1953: 15; Çüy Bölgesi Bakinova \& Konduchalova, 1958: 78). Yudahin (I. 199) dönön sözcüğünün Kırgızistan'ın güneyinde bıştı $(<b \iota s ̧-t \imath)$ sözcügüüle aynı anlama geldiğini ve çarı koy olarak da adlandırıldığını dile getirmiştir. Oktyabr' ve Özbekistan'da yaşayan Kırgızlarda da dört yaşındaki koyun için çarı sözcüğünün kullanıldığı bilinmektedir. (bk. Oktyabr’ Ağızı Bakinova, 1953: 15; Özb. Kırg. Abduldaev \& Bakınova, 1962: 159). Kazak Türkçesinde (KazRS 149) Özbek Türkçesinde (ÖzbRS 136) dönen sözcüğünün üç yaşındaki ata ve dört yaşındaki koyuna verilen bir isim olduğu görülmektedir. Yeni Uygurcada (Y.UygTS 106) dört yaşında olan hayvanların geneli dönen sözcüğüyle adlandırılmaktadır. İstanbul' da yaşayan Kırım göçmenlerinin ağzında dönen (DS II, 1584a) sözcüğü “üç yaşını bitirip dört yaşına basan tay, sığır” anlamıyla geçer.

Dönen ve çarı sözcüklerinin etimolojisine bak1lırsa dönen Moğolcadan (Lessing 267b dön-en / dönö 'dört yaşındaki erkek hayvan') çar Farsçadan (Steingass 384 çar 'dört') ödünçlemedir.

1.10. Beş yaşındaki koyun: Kırgızistan’ın kuzey bölgesinde beş dişli koyunlara herhangi bir isim verilmiyor. Çobanların verdiği bilgilere göre beş dişli koyuna veya yaşlanmış koyuna mama adı verilir. Yudahin'in sözlüğünde (II 15) mama (< far. Steingass 1316: 'meme') sözcügünün Tiyanşan bölgesinde yaşlanmış kısrak için kullanıldı̆̆ı belirtilmiştir. Bazı yerlerde subay koy adı da kullanılmaktadır. Subay sözcüğünün asıl anlamı "doğuran”, ancak Yudahin'in sözlüğünde (II 162) subay sözcüğünün ikinci anlamı "çocuksuz, çocuk doğurmayan” olarak geçmektedir. Ancak Kırgızistan’ın güney bölgelerinde beş yaşındaki koyun panci koy olarak adlandırılmaktadır. Oktyabr' ağzında ve Özbekistan'daki Kırgızların ağzında panci “beş yaşındaki koyun" beş yaş üstüne de şaş sözcüğünün kullanıldığı görülmektedir (bk. Oktyabr’ Ağızı Bakinova, 1953: 15; Özb. Kırg. Abduldaev \& Bakınova, 1962: 159). Her iki sözcük de Farsçadan (Steingass 256 panc 'beş'; 744 şaş 'altı) ödünçlemedir. Beş yaşındaki koyun için verilen adlar hem komşu Türk dillerinde hem de Türkiye Türkçesinde bulunmamaktadır. Kazak Türkçesinde mama biye "yavrusu olan veya yavrulamış kısrak" (KazTR 194) olarak geçmektedir ve Özbek Türkçesinde moma sözcüğü “süt veren” (ÖzbRS 266) anlamı ile bilinmektedir.

\section{BÜYÜKBAŞ HAYVANLAR}

Çalışmanın bu bölümünde büyükbaş hayvanlardan olan inek ve at üzerinde durulacaktır.

\section{Inek}

1.1. тиzоo (bözök): Yudahin II 37 Rus. теленок “yeni doğmuş buzağı”. Kırgız Türkçesinin bütün ağızlarında bilinmektedir ancak anlam bakımından değişikliğe uğramıştır. Calal-Abad 
ağızlarında: muzoo (bk. Bakinova \& Konduchalova, 1958: 107); Oktyabr' ağızında ve Özb. Kırg.: torpok “yeni doğmuş buzağı” (bk. Oktyabr’ Ağızı Bakınova, 1953: 15; Özb. Kırg. Abduldaev \& Bakınova, 1962: 159). Kırgızistan'ın kuzeyinde genellikle yeni doğana muzoo adını verirler. Komşu Türk dillerinde de Eski Türkçe buzağu (Clauson 391a) sözcüğüne daha yakın biçimler görülmektedir: KazTS 51 buzav, ÖzbRS 88 buzak; Yeni Uygurcada ise hem yeni doğana hem de bir yaşına giren buzağıya topaq (Y.UygTS 420) adı verilmektedir. Türkiye Türkçesinde de buză̆ $b$ - sesleri Kırgız Türkçesinde eğer ilk hecenin sonunda bir - $n$ - sesi varsa (örneğin ben > men, bunu > munu gibi) genellikle $m$ - sesine dönüşür. Fakat ilk hecenin sonunda $-n$ - sesinin bulunmamasına rağmen bazen $b$ - > $m$ - gibi dönüşebiliyor, örneğin $b u z>m u z$. Schönig (2002: 257) bu gibi değişimi 'kendiliğinden değişim' (spontanen Wandel) olarak adlandırmaktadır. Schönig'e göre bu tarz değişimler Batı Oğuz Türk dilleri dışındaki birçok Türk dillerinde görülebilir (bk. Schönig, 2002). Kırgız Türkçesindeki muzoo < buzağu sözcüğünün Türkçe kelime olduğu görülmektedir: DLT 194 buzagu; Clauson (391a) buzagu sözcüğünün çok eski bir sözcük olduğunu belirtmiştir.

1.2. Torpok: Yudahin II 254 Rus. теленок “altı aylık ancak bir yaşını doldurmamış buzağı”. Kırgızistan'ın güneyinde yeni doğan ve bir yaşına girmemiş olan buzağıya da torpok adı verilir. Kırgızistan'ın kuzeyinde ise altı aylık ve bir yaşına girmemiş buzağıya torpok denilir. Kazak Türkçesinde torpak "altı aydan büyük ve bir yaşa gelmemiş buzağı” (KazTS 274) ve Yeni Uygur Türkçesinde topak "dana, buzağı” (Y.UygTS 420) anlamındadır. Özbek Türkçesi ve Türkiye Türkçesinde torpak / topak sözcükleri bilinmemektedir.

Clauson'a (533a) göre torp (DLT 179 torp ı "buzağı"; Räsänen 490b torpak "iki yaşındaki dana”) sözcüğü "takip eden; annesini takip eden” anlamına gelmektedir. Torpok biçimi torpı sözcüğünden türemiş olabilir: torpok / torpak / topak $(<$ torp $l-k)$. Sözcüğün anlamına bakılırsa buzağı altı ayında da hâlâ annesinin peşinden gider ve anlam bakımından eşleşmektedir. Clauson'a göre bu sözcük Kırgız, Kazak ve Yeni Uygur Türkçeleri dışında Sibirya Türk dillerinde de (AltTS 182 torbok, HakRS 233. torbax) varlığını sürdürmektedir.

Komşu Türk dillerinin sözlüklerinde yaşlarına göre ayrıntılı adlandırmayı bulmak hayli zordu. Kaynak kişilerden elde ettiğim bilgilere dayanarak bazıları tarafımdan eklenmiştir. Kırgız Türkçesinde buzağı iki yaşından itibaren şu şekilde adlandırılmaktadır.

1.3. Kunan torpok: Kırgız Türkçesinin ağızlarında da muzoo "buzağı" anlamındadır. Buzağının iki yaşına girmiş hem dişisi hem de erkeğine farklı adlar verilmektedir. Kırgızistan'ın kuzeyinde ve Calal-Abad ağızlarında kunan torpok ile "iki yaşındaki dana" ifade edilmektedir (bk. Calal-Abad Ağızı Bakinova \& Konduchalova, 1958: 107). Kazakistan'da yaşayan Kırgız ağızlarında iki yaşındaki erkek buzağıya tana denilmektedir (bk. Kazakistan'daki Kırgızlar Beysekeev, 1964: 62). Yudahin'in sözlüğünde (II. 202) tana “iki yaşındaki inek"; torpok-tana da iki yaşındaki erkek ve dişi anlamındadır. Kazak Türkçesinde tana "dana; bir yaşına gelmiş sığır” (KazTS 262), Özbek Türkçesinde tana “iki yaşındaki dişi inek yavrusu” (ÖzbRS 404), 
Yeni Uygur Türkçesinde tana “dana” (Y.UygTS 388) olarak bilinmektedir. Türkiye Türkçesinin ağızlarında dana, düve sözcükleri geçer. Mehmet Akbaş'ın (Samsun, Bafra Şeyh Ören) ve Celal Gezer' in (Manisa, Akhisar) verdikleri bilgilere göre düve (bk. kunacın) daha doğurmamış dişisine, dana ise erkeğine verilen addır. Hasan Aydın'ın (Sivas, Yıldız Beldesi) verdiği bilgiye göre dana, düve dışında da bir yaşını doldurmamış erkek veya dişiye körpe (< görpe: Eren 259b 'yerel ağızlarda yeni doğan kuzu veya oğlak' için de kullanılır), bir yaşını dolduran erkek veya dişiye yaşar (<yaşa-r) adı verilir. Eren (105a) etimolojik sözlüğünde dana "ineğin iki yaşına kadar olan erkek yavrusu", (127a) düve "bir yaşını geçmiş dişi dana" ile ayrıntılı bilgi vermektedir. OT'de tüge "ineğin iki yaşına gelmemiş erkek yavrusu için kullanılırken dişisi tişi tüge (DLT 446) kullanılmaktadır. Clauson'a (478b) göre tüge "iki yaşına gelmemiş buzağı” sözcüğü Oğuz grubunda korunmuştur. Orta Türkçede tana sözcüğünün bilinmemesi ancak Türk dillerinde, özellikle Fergana bölgesi ve Oğuz grubunda “iki yaşına girmemiş erkek yavru” anlamı ile karşımıza çıkması düşündürücüdür. Seydakmatov (63) torpok, toropoy, kulun sözcüklerinin kökünü Yunanca bortaks, Sanskritçede bortukas sözcüklerine bağlamaktadır. Ancak Seydakmatov’un görüşü tartışılmalıdır.

1.4. Kunan kunayın/kunacın: Yudahin I 445 телка (коровы и оленя) “hiç buzağılamamış inek”. Kırgız Türkçesinin bütün ağızlarında bulunmaktadır (bk. Bakinova \& Konduchalova, 1958: 107). Ancak hiç buzağılamamış inek dört yaşına kadar her yıl için ayrı bir isimle adlandırılır: tay kunacın "iki yaşındaki hiç buzağılamamış inek", kunan kunacın "üç yaşındaki hiç buzağılamamış inek", bıştı kunacın "dört yaşındaki hiç buzağılamamış inek". Bu adlandırmalar Kırgız Türkçesinin ağızlarının birçoğunda özellikle Kırgızistan’ın güney ağızlarında bilinmemektedir. Talas bölgesinde ise sözcüğün kunayın biçimi geçmektedir. Komşu Türk dillerine bakılırsa Kazak Türkçesinde kunacın (KazRS 299), Yeni Uygur Türkçesinde ġunucu (Y.UygTS 146) “üç yaşındaki dişi sığır” anlamıyla geçmektedir. Özbek Türkçesinde ise "üç yaşındaki dişi sığır” için kulon (bk. kunan) (ÖzbRS 629) sözcüğü kullanılmaktadır. Çağataycada kunocın sözcüğü “üç yaşındaki dişi tay“ anlamıyla bilinmektedir (Räsänen 300b). Türkiye Türkçesinde ise kunacın sözcüğü bulunmamaktadır, "üç yaşındaki dişi sığır veya buzağılamamış dişi” için düve sözcüğü kullanılmaktadır (bk. düve). Kunacın sözcüğü Moğolca gunji(n) (Lessing 368a “üç yaşındaki dişi sığır”) sözcüğünden ödünçleme bir kelimedir (kş. Räsänen 301a; Seydakmatov 161).

1.5. Uy / sıyır: Yudahin I 300 корова “inek”. Kırgız Türkçesinin ağılarının çoğunda uy “inek” biçimi kullanılmaktadır, ancak Kırgızistan’ın güneyindeki İçkilik ağızlarında, Kazakistan' da ve Özbekistan' da yaşayan Kırgızların ağzında sıyır sözcüğü kullanılmaktadır (bk. Beysekeev, 1964: 62; Bakinova \& Konduchalova, 1958: 107; Abduldaev \& Bakinova, 1962: 159). Özbekistan'da yaşayan bazı İçkilik boyuna mensup Kırgızlarda inek için de pada (< Moğ. boda I Lessing 108b 'büyük baş hayvan') sözcüğü kullanılmaktadır (bk. Özb.Kırg. Abduldaev \& Bakinova, 1962: 159). Abduldaev ve Bakinova’ya göre inek, koyun, keçi güden kişiye de padaçı veya çekeneçi denmektedir. Çekene sözcügünün de Tacikçeden alıntı bir kelime olup “özel, tane, yalnız ve ufak" anlamlarına geldiğini dile getirmişlerdir. Özbekistan' da yaşayan İçkilik boyuna mensup Kırgızlarda az sayıda veya kendine ait olan hayvanlara bakan kişiye 
çekeneçi adı verilmektedir. Dikkate değer bir diğer husus ise sıyır sözcüğünün Çüy bölgesinin batı tarafında bilinmesidir (Bakinova, 1958: 78). Çüy bölgesinin Kazakistan'a sınır bölgelerinde sıyır biçimi kullanıldığı tahmin edilebilir çünkü Kazak Türkçesinde “inek” için sıyır sözcüğü kullanılmaktadır. Yudahin’e (300) göre $u y$ sözcüğü Kırgızistan’ın güneydeki bazı bölgelerinde cündüü uy (topoz, rus. як) veya tuvar uy "doğuran inek" anlamlarıyla bilinmektedir. Abduldaev ve Bakinova (1962: 159) araştırmalarına göre Özbekistan'daki Kırgız ağızlarda mal, uy, sıyır sözcüklerinin "inek” anlamıyla bilindiğini belirtmişlerdir. Komşu Türk dillerinde, Kazak Türkçesinde slyır (KazTS 242), Özbek Türkçesinde sigir (ÖzbRS 365) ancak Yeni Uygur Türkçesinde kala "inek”, uy "öküz” (Y.UygTS 441; 635) biçimleri bulunmaktadır. Türkiye Türkçesinde ise inek sözcügü kullanılmaktadır.

Uy, slyır ve inek sözcüklerinin etimolojisine bakılırsa, her üç sözcük de ET'de bilinmektedir: uy < ud (DLT 21) (Çigil Lehçesinde sığır), (Clauson 34a) "büyük baş hayvan; öküz; Eski Türklerde kullanılan 12 hayvanlı takvimdeki yıl adıdır', Räsänen 509b “inek, sığır”, EUD 254 “sığır”, Seydakmatov 234; slyır < sığır (DLT 156) “sığır, camız, su sığırı”, (Clauson 814b) "büyük baş hayvan", (Räsänen 414b), (Eren 364a) "etinden ve sütünden yararlanılan, boynuzlu büyük evcil hayvan"; inek < ingek (Clauson 184a), (DLT 54), (Eren 191b) “dış1 sığır”, (Räsänen 172a), (Seydakmatov 117). Kırgızistan'ın kuzeyinde topozun “yak” dişisine de inek denilmektedir.

1.6. Buka: Yudahin I 156 Rus. бык-производитель "boğa; ineğin erkeği“. Hem Kırgız Türkçesinin bütün ağızlarında hem de komşu Türk dillerinde bu sözcük bilinmektedir: KazTS 52, ÖzbRS 93: buka, Y.UygTS 46 bog $a$ “enenmiş erkek sığır”; bk. DLT 445 buka "ineğin erkeği”, Clauson 312a buka “erkek sığgir”; EUD 92, Räsänen 87a buka.

Türkiye Türkçesinde boğa “damızlık erkek sığır” (TTürS 370) biçimi ile bilinmektedir. Türk dillerinde sözcük bazı fonetik değişikliklerle (u/o, k/ğg) görülmektedir. Sözcüğün etimolojisiyle ilgi ayrıntılı bir bilgi bulunmamaktadır. Dilbilimciler Türk dillerindeki buka / boğa biçiminin Moğolca buġa "erkek geyik“ (Lessing 131a) sözcüğü ile karıştırılmaması gerektiğini ifade etmişlerdir. Moğolcada buğa "erkek geyik“ sözcüğü dişında da buxa "boğa" (Lessing 142b) sözcügü bilinmektedir. Moğolcadaki buxa "boğa" sözcüğü Kalmukçada buxa (KalmRS 123) biçimi ile görülmektedir. Türk dillerindeki buka sözcüğünün kökü büyük ihtimalle Moğolca buxa sözcüğüne dayanmaktadır.

1.7. Noovas/ noopas /oopaz: Yudahin II 75 “dört yaşındaki enenmiş boğa”. Kırgız Türkçesinin güney ağızlarının bazılarında bilinmektedir. Calal-Abad bölgesinin bazı illerinde üç veya dört yaşındaki enenmiş boğaya noovas /noopas / oopaz denilmektedir (bk. Calal-Abad Ağızı Bakinova \& Konduchalova, 1958: 106). Özbek Türkçesinde novvos “iki veya üç yaşındaki boğa” (ÖzbRS 287) biçimi bilinmektedir. Seydakmatov'a göre (187) noopas (< Far. nawbastan Steingass 1428, 186: 'yeni-bağlanmak') sözcüğü Farsçadan ödünçleme olup “yeni tarlaya sürülen, arabaya yeni çekilmiş genç erkek sığı’” anlamındadır.

3 Uwe Bläsing (2003: 229), Kalmuck. In. The Mongolic Languages. Ed. Juha Janhunen. Routledge. London \& New York. 
1.8. Ögüz: Yudahin II 88 “enenmiş boğa”; kunan ögüz "üç yaşında”, bıştı ögüz "dört yaşında”, asıy ögüz “beş yaşında”. Kırgızistan'ın güneyinde hayvanın yaşlarına göre yapılan bu adlandırmaların hiçbiri bilinmemektedir. Eski Türkçeden beri kullanılan bir sözcüktür: DLT 786, EUD 192, Clauson 120a, Räsänen 370b (h)öküz). Komşu Türk dillerinde de yaygın kullanılan bir sözcüktür: KazTS 213 ögiz, ÖzbRS 665 hökiz, Y.UygTS 157 höküz "enenmiş erkek sığır”. Eren (314b), öküz sözcüğünün "çift sürmekte, araba çekmekte kullanılan etinden yararlanılan iğdiş edilmiş sığır” anlamıyla vermiştir. Eren, öküz sözcüğünün de kökeninin karışık olduğunu belirtmiş ancak bazı dilbilimcilerin sözcüğün kökeni ile ilgili görüşlerine çalışmasında yer vermiştir (bk. Eren 314b).

2. At

2.1. Kulun: Yudahin I 443 Rus. жеребенок “уeni doğan kısrak yavrusu”. Kırgız Türkçesinin bütün ağızlarında bulunmaktadır. Sözcük hem komşu Türk dillerinde hem de Türkiye Türkçesinde bilinmektedir: KazRS 299 kulın, ÖzbRS 630 kulun, Y.UygTS 146 gulun "yaşını doldurmamış kısrak yavrusu"; TTür. kulun "at yavrusu”; DS (III, 2998a) "at ve eşek yavrusu”. Yerel ağızlarda gulun eşek yavrusu, sıpa olarak kullanılır (bk. Eren 264b). EUD 168, Clauson 622b kulun "doğumundan bir yaşına kadar olan kısrak yavrusu”. DTL 174 kulun "tay”.

Seydakmatov (160) sözcüğün etimolojisini ET oğul sözcüğüne bağlamıştır. Ona göre gulun sözcügü, ET oğul sözcüğünün 3. Tekil şahıs iyelik eki almış ve söz başı $o$ - sesinin düşmüş biçimidir. Brokelmann (OGM 55) da sözcüğün -un ekiyle türediğini savunmuştur. Joki (1952: 208-209) kulun sözcüğünün eski bir 'Seyyah Sözcük' olabileceğini düşünmüştür ve örnek olarak da Akkadça kudûnu, kudânu, kudîni "katır" biçimlerini vermiştir. Ancak Doerfer (TMEN 1523) Akkadçadaki kudûnu, kudânu, kudîni sözcüklerinin hem ses bakımından hem de anlam bakımından kulun sözcüğüyle uyuşmadığını ve bununla birlikte coğrafî ara evrelerinin eksik olduğunu belirtmiştir.

2.2. Tay: Yudahin II 190 "bir yaşını doldurup iki yaşına girmemiş olan at yavrusu”. Kırgız Türkçesinde genellikle bir yaşına giren büyük baş hayvanlar için de söylenmektedir Kırgız Türkçesinin bütün ağızlarında bilinen sözcük Özbekistan'da yaşayan Kırgızların ağızında kelte tay "bir buçuk yaşında olan at yavrusu" biçiminde kullanılmaktadır (bk. Özb. Kırg. Abduldaev \& Bakınova, 1962: 160). Komşu Türk dillerinde ve Türkiye Türkçesinde de tay sözcüğü geçmektedir: KazRS (432) tay "bir yaşındaki at yavrusu”, ÖzbRS (440) toy "iki yaşındaki at yavrusu", Y.UygTS (395) tayçak "at yavrusu”, Eren (398b) tay "üç yaşına kadar olan at yavrusu"; Clauson (556b) tay "bir ve iki yaşlarındaki at yavrusu”. DLT (100): yaşı belirtilmemiş. Doerfer (TMEN 863) tay “iki yaşını doldurmamış at yavrusu: Jungpferd”. Räsänen (455a) tay "yeni doğan: Füllen”.

2.3. Kunan: Yudahin I 445 “üç yaşındaki at yavrusu; üç yaşında olan büyük baş hayvanlar”. Kırgız Türkçesinin bütün ağızlarında bilinmektedir, özellikle Talas bölgesinde üç yaşında olan koyun için de kunan koy biçimi görülmektedir (kş. Seydakmatov 161). Hem Kazak Türkçesinde kunan (KazRS 299) ve hem de Yeni Uygur Türkçesinde ġunan (Y.UygTS 146) “üç yaşındaki 
at yavrusu" görülmektedir ancak Özbek Türkçesiyle kunan sözcüğü bilinmemektedir. Türkiye Türkçesinin ağılarında kulan sözcüğü “iki veya üç yaşlarında dişi tay, kısrak” (DS III, 2996a) bilinir. Sarı Uygurcada kunan "iki veya üç yaşındaki öküz” anlamı geçmektedir (bk. Malov, 1957: 61a; Räsänen 300b Çağ., Oyrt., Tel., Leb., Kaz. kunan “iki veya üç yaşındaki at yavrusu”). Sözcük Moğolcadan ödünçlemedir: kunan < guna(n) "üç yaşında olan hayvanlar” (Lessing 368a); KalmRS (608) xul /kulan "yabani at".

2.4. Baytal: Yudahin I 98 Rus. кобылица "yavrulamamış genç kısrak". Tay baytal "iki yaşında”, kunan baytal “üç yaşında”, bıştı baytal "dört yaşında”. Kırgızistan'ın güney ağızlarında baytal sözcüğü atın dişisi için kullanılan genel bir adlandırmadır. Baytal sözcüğü komşu Türk dillerinde kullanılmaktadır: KazRS 84, ÖzbRS 51, Y.UygTS 33 baytal "kısrak, doğurmamış kısrak”. Türkiye Türkçesinde baytal sözcügü bilinmemektedir ancak Räsänen (57b) baytal sözcügünün Osmanlı Türkçesinde de geçtiğini belirtmiştir; OsmTürS (169a) baytal "üç yaşını geçmemiş kısrak”. Moğolcada baydas/baydasun (Lessing 74a) sözcüğü “üç veya dört yaşındaki hiç doğurmamış hayvan” anlamıyla geçer. Doerfer TMEN 827 baytal sözcüğünün Moğolcadan Türkçeye geri ödünçleme (Rückentlehnung) olabileceğini öne sürmüştür: baytasun < *baytal -sun (Moğ. -sun eki eski bir teklik bildiren ek olduğunu belirtmiştir).

2.5. Bee: Yudahin I 175; Kısrak Yudahin I 499 “genç dişi kısrak”. Kırgız Türkçesinin ağızlarında bee biçimi geçer. Yudahin kısrak biçiminin hangi ağızlarda kullanıldığını belirtmemiştir. Kırgızistan’ın kuzeyinde kısrak annesini hâlâ emen tay için kullanılır. Özbekistan'daki Kırgızların ağızlarında hem bee hem de biye biçimleri kullanılmaktadır (bk. Özb. Kırg. Abduldaev \& Bakınova, 1962: 160). Komşu Türk dillerinde bee sözcüğü geçmektedir: KazTS. 46 biye, ÖzbRS 77 biya, 61. Hem Yeni Uygur Türkçesinde (Y.Uyg. 196 baltay, 198 baytal 'yavurlamamış kısrak') hem de Türkiye Türkçesinde (kısrak 'dişi at': bk Eren 240b) bee ya da biye sözcükleri bilinmemektedir. Sözcük daha çok Sibirya Türk dillerinde bilinmektedir: Clauson 291b be "dişi"; Alt., Leb., Tel., pe; Hak., Tuv. be. DLT 437, Çağ. bi. Räsänen (75b), sözcüğünün etimolojisini şu şekilde düşünmüştür: Madjucada biren "dişi kaplan", bi-msu / bi-mšu "keklik tavuk" sözcükleri bilinmektedir; Sinokorecede $p i$ sözcügü “dişi”, pija sözcüğü ise "dişi köle” anlamlarına gelmektedir. Bu iki dilden Türkçeye alındığı konusu tartışmaya açıktır.

2.6. Aygır: Yudahin I 29 Rus. жеребеu “damızlık erkek at”. Özbekistan’da yaşayan Kırgızların ağızlarında hem agır hem de aygır biçimleri kullanılmaktadır (kş. Özb. Kırg. Abduldaev \& Bakınova, 1962: 159). Eski Türkçeden başlayarak adġır sözcüğü bilinmektedir:

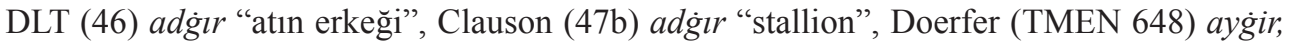
Räsänen (6a) adg்ır. "Hengst”. Çağdaş Türk dillerinde sözcük ses değişikleriyle karşımıza çıkmaktadır: KazRS (30) aygır, Y.UygTS (24), ÖzbRS (29) ayġir, TTür. aygır "damızlık erkek at" (bk. Eren 27a).

Sözcügün köküyle ilgili farklı görüşler vardır. Bazı bilim adamları Türkçedeki aygır / adġır sözcüğüyle Moğolcada acırga (Lessing 62b) sözcüğünün bir bağlantısı olabileceğini öne 
sürmüşlerdir. Doerfer (TMEN 648) ay- "trennen: ayırmak" kökünden geldiğini düşünmüştür. Sevortyan’a (1974: 108) göre sözcüğün kökü $a z$ - fiilinden türemiştir ve Seydakmatov (14) da bu görüşü desteklemektedir. Ancak Eren (27a) Sevortyan'ın bu açıklamasının ses yönünden olanaksız olduğunu belirtmiştir.

2.7. At: Yudahin I 77 Rus. лошадь, конь “enenmiş aygır; hem binek hem de iş için kullanılan hayvan”. Hem Eski Türkçede hem de Çağdaş Türk Lehçelerinde at olarak geçer: DLT (12), Clauson (33a), EUD (59), Doerfer (TMEN 13), Eren (24a); KazTS (22) at, ÖzbRS (308) ot I “binek at”, Y.UygTS (19) at. Doerfer'e göre at sözcüğü Türkçeden komşu dillere geçmiştir. Moğolcada at için morin (Lessing 543b) sözcüğü kullanılır. Moğolcada bir de ata "enenmiş deve" (Lessing 58a) sözcügü geçer. Kalmukçada at için mörn (KalmRS 360) biçimi geçer. Rusçada ata verilen лошадь isminin Türk dillerinden alındığı düşünülmektedir (ayrıntılı bk. Eren 24a).

2.8. Asıy: Kırgız Türkçesinde atın yaşı beş yaşından sonra asıy terimi ile ifade edilir (Yudahin I 76). Bu sözcük Kırgız Türkçesinin ağızlarında geçer. Hem Eski Türkçede hem de Orta Türkçede asıy sözcüğü bilinmemektedir. Çağdaş Türk lehçelerinin çoğunda asıy sözcüğü geçmemektedir. Kazak Türkçesinde ası "bir yaşında", Tel., Sag., Koib. ası "bir yaş öncesi” anlamlarıyla bilinmektedir (bk. Räsänen 29a). Hakas Türkçesinde (HakRS 18) azıy sözcüğü “önceki, geçmiş, eski” anlamlarıyla geçmektedir.

\section{SONUÇ}

Bu çalışmada, Kırgız Türkçesinde küçükbaş (koy) ve büyükbaş (uy, at) hayvanların yaşlarına göre yapılan adlandırmalar çobanların verdikleri bilgilere ve Kırgız Türkçesinin ağızlarından derlenen çalışmalara dayanarak toplanmıştır. Tespit ettiğimiz adlandırmalar coğrafi bakımdan komşu olan Kazak, Özbek ve Yeni Uygur Türkçeleriyle karşıllaştırılmıştır. Bunun yanı sıra adlandırmalar Türkiye Türkçesinde de taranmıştır. Küçükbaş (koy) ve büyükbaş (uy, at) hayvanların yaşlarına göre verilen adların etimolojisi incelenmeye çalışılmış ve Moğolca, Farsça kaynaklarla da karşılaştırılmıştır. Araştırmanın sonucuna göre küçükbaş (koy) ve büyükbaş (uy, at) hayvanların yaşlarına göre verilen adların bazılarının Kırgız Türkçesinin ağızlarında aynı anlamda kullanılmadığg bazılarının ise belli ağızlarda bilindiği tespit edilmiştir. Adların çoğu karşılaştırılan diğer Türk dillerinde bazı ses değişikleri ile yaşamaktadır (kozu, koy, toktu, şişek, dönön; muzoo, uy, sığır, inek, buka, ögüz; kulun, tay, kunan, aygır, at). Bazı sözcükler (boruk, cusak, bee) karşılaştırılan diğer Türk dillerinde tespit edilmemiştir. Kırgız Türkçesinde küçükbaş ve büyükbaş hayvanların yaşlarına göre yapılan adlandırmalar diğer dillerle karşılaştırılarak aşağıdaki tablolarda özetlenmiştir. 
Tablo I. Küçükbaş hayvan (koy)

\begin{tabular}{|c|c|c|c|c|c|c|}
\hline Kırg./ĂğıZ & Kaz. & Özb. & Y.Uyg. & TTür. & ET & Anlamları \\
\hline koy & koy & koy & koy & Koyun & ko:ń & Genel adlandirma \\
\hline kozu & koz1 & kuzi & koza & Kuzu & kuzi & Yeni doğmuş koyun yavrusu \\
\hline toktu & tokt1 & tohli & tohlu & Toklu & tokl1 & Kuzulamamış dişi \\
\hline boruk & - & - & - & $\begin{array}{l}\text { toklu,şişek, } \\
\text { makak }\end{array}$ & - & 1, 2 yaşında olan erkek kuzu \\
\hline cusak (GK) & - & - & - & - & - & $\begin{array}{l}2 \text { yaşındaki koyun yavrusu; } \\
\text { GK: genç keçi }\end{array}$ \\
\hline şişek (GK & - & şişak & - & Şişek & tişek & $\begin{array}{l}2 \text { yaşındaki koyun; } \\
\text { kuzulamamış koyun }\end{array}$ \\
\hline $\begin{array}{l}\text { kunan koy } \\
\text { sooluk }\end{array}$ & - & - & sağlık & - & & 3 yaşındaki koyun \\
\hline irik & - & - & erik 'koyun' & $\begin{array}{l}\text { erkeç } \\
\text { 'enenmiş keçi' }\end{array}$ & irk & 3 yaşındaki enenmiş koç \\
\hline dönön/tögörök & dönen & dönen & dönen & - & - & 4 yaşındaki koyun \\
\hline $\begin{array}{l}\text { mama / subay }(\mathrm{KK}) \\
\text { panc koy }(\mathrm{GK})\end{array}$ & mama biye & moma & - & - & - & 5 yaşındaki koyun \\
\hline
\end{tabular}

\section{Tablo II. Büyükbaş hayvan}

\begin{tabular}{|l|l|l|l|l|l|l|}
\hline Kırg./Ağız & Kaz. & Özb. & Y.Uyg. & TTür. & ET & Anlamları \\
\hline muzoo & buzav & buzak & topak & Buzağı & buzagu & Yeni doğan inek yavrusu \\
\hline torpok & torpak & - & topak & - & torp1 & 6-1 yaş arası inek yavrusu \\
\hline kunan torpok & tana & tana & tana & Dana & & 2 yaşındaki inek yavrusu \\
\hline kunacın & kunacın & kulon & ġunucu & Düve & tüge & Hiç buzağılamamış inek \\
\hline $\begin{array}{l}\text { uy } \\
\text { sıyır (İçkl.Ağ) }\end{array}$ & sııır & sigir & kala & İnek & ud/sı̇̇ır & inek \\
\hline buka & buka & buka & bog்a & boġa & buka & İneğin erkeği \\
\hline noopas & - & novvos & - & - & - & 4 yaşındaki enenmiş boğa \\
\hline ögüz & ögiz & hökiz & höküs & öküz & (h)öküs & Enenmiş boğa \\
\hline
\end{tabular}

\begin{tabular}{|l|l|l|l|l|l|l|}
\hline Kırg./Ăğız & Kaz. & Özb. & Y.Uyg. & TTür. & ET & Anlamları \\
\hline kulun & kulın & kulun & gulun & kulun & kulun & Yeni doğan kısrak yavrusu \\
\hline tay & tay & toy & tayçak & tay & tay & $\begin{array}{l}\text { 1 yaşını doldurup 2 yaşına } \\
\text { girmemiş olan at yavrusu }\end{array}$ \\
\hline kunan & kunan & - & ġunan & - & - & $\begin{array}{l}\text { 3 yaşında olan büyük baş } \\
\text { hayvan }\end{array}$ \\
\hline baytal & baytal & baytal & baytal & - & - & Yavrulamamış genç kısrak \\
\hline bee & biye & biya & baytal & kısrak & be & kısrak \\
\hline aygır & aygır & ayġır & ayġır & aygır & adġır & Damızlık erkek at \\
\hline at & at & at & at & at & at & Enenmiş aygır \\
\hline asıy & ası & - & - & - & - & 5 yaşından itibaren kullanılan \\
\hline
\end{tabular}


Hakem Değerlendirmesi: Dış bağımsız.

Çıkar Çatışması: Yazar çıkar çatışması bildirmemiştir.

Finansal Destek: Yazar bu çalışma için finansal destek almadığını beyan etmiştir.

Peer-review: Externally peer-reviewed.

Conflict of Interest: The author has no conflict of interest to declare.

Grant Support: The author declared that this study has received no financial support.

\section{KAYNAKÇA/REFERENCES}

Abduldaev, E., Bakinova, G., Beyşekeev, N. (1962). Özbekstandık Kırgızdardın tilindegi cergiliktüü özgöçölüktör. Frunze: Kırgız SSR IA.

Akabirova, S.F. (1959). Uzbeksko- Russkiy Slovar'. Moskva.

Ayazlı, Ö. (2016). Eski Uygurca Din Dışı Metinlerin Karşılaştırmalı Söz Varlı̆̆ı. Ankara: Türk Dil Kurumu.

Bakeev, K. (1952). Nookatskiy govor Oşskoy oblasti. Alma-Ata: AN Kaz. SSR.

Bakinova, G. (1953). Kirgizskiy govor Oktyabr skogo rayona. Frunze.

Bakinova, G. (1955). Isık-Köl govorunun Materiyalınan. Frunze.

Bakinova, G., Konduçalova, S., Sidıkov, S. (1958). Kırgız tilinin Calal-Abad govorloru. Frunze.

Bakinova, G. (1956). Kırgız tilinin Oş govoru. Frunze.

Bakinova, G. (1959). Kırgız tilinin Çüy govoru. Frunze.

Bazin, L. (1967). Noms de la 'Chévre’en Turc et en Mongol. Studia Altaica. Festschrift für Nikolaus Poppe zum 60. Geburstag. Wiesbaden: 28-32.

Baskakov, N. A. (1953). Hakassko-Russkiy Slovar’. Ministerstvo Kul’turı SSSR. Moskva.

Baskakov, N. A. (1961). Russko-Altayskiy Slovar'. Sovetskaya Ensklopediya. Moskva.

Bektaev, K. (1991). Kazahsko-Russkiy Slovar’. Alma-Ata.

Beyşekeev, N. (1960). Murgabdık Kırgızdardın leksikalık özgöçölüktörü boyunca materiyaldar. Kırgız SSR. IA. TAI. Kabarları 1. Çıgıışı.

Beyşekeev, N. (1964). Kazakstandagı Kırgızdardın tildik özgöçölüktörü. Frunze: Kırgız SSR Akademiyasının Basmasi.

Bläsing, U. (2003). Kalmuck. In: The Mongolic Languages. Ed. Juha Janhunen. London \& New York: Routledge.

Çağbayır, Y. (2017). Osmanlı Türkçesi Sözlüğü. İstanbul: Ötüken.

Diykanov, K. (1980). Kırgız Tilinin Tarıhınan. Frunze: Mektep.

Doerfer, G. (1975). Türkische und Mongolische Elemente im Neupersischen. Wiesbaden: Franz Steiner. Eren, H. (1999). Türk Dilinin Etimolojik Sözlüğ̈̈. 2. Bask1. Ankara: A.Ü. Dil ve Coğrafya Fakültesi.

Ercilasun, A.B., Akkoyunlu, Z. (2015). Divanü Lûgat-it-Türk Tercümesi III. 2. Bask1. Ankara: Türk Dil Kurumu.

Joki, A.J. (1952). Die Lehnwörter des Sajansomjedischen. Helsinki: Mémoires de la Société FinnoOugrienne 103.

Kültür Bakanlığı (1991). Karşılaştırmalı Türk Lehçeleri Sözlüğü. Ankara: Kaynak Eserler 54. 
Lessing, F. D. (1960). Mongolian-English Dictionary. Los Angeles: University of California Press.

Malov, S. Y. (1957). Yazık jyoltıh uygurov: Slovar' i Grammatika. Alma-Ata.

Munieva, B. D. (1977). Kalmıkscko-Russkiy Slovar’. Moskva: Russkiy Yazık.

Nadjip, E. N. (1968). Uygursko-Russkiy Slovar’. Moskva: Sovetskaya Ensklopediya.

Nadjip, E. N. (1995). Yeni Uygur Türkçesi Sözlüğü. Çev. İklil Kurban. Ankara: Türk Dil Kurumu.

Oraltay, H. (1984). Kazak Türkçesi Sözlüğ̈̈. Ter. Nuri Yüce, Saadet Pınar. İstanbul: Türk Dünyası Araştırmaları.

Ramstedt, G. J. (1935). Kalmükisches Wörterbuch. Lexica Societatis Fenno-Ugricae 3. Helsinki.

Ramstedt, G. J. (1943-53). Studies in Korean Etymology. Helsinki: Mémoires de la Société Finno-Ougrienne 103. XCV.

Räsänän, M. (1969). Versuch eines etymologischen Wörterbuchs der Türksprachen. Helsinki: Lexica Societatis Fenno-Ugricae XVII.

Schönig, C. (1997). A new attempt to classify the Turkic Languages (1). Wiesbaden: Turkic Languages 1, s. 117-133.

Schönig, C. (2000b). Mongolian Loanwords in Oghuz as indicators of linguistic and cultural areas in Southwest Asia. Wiesbaden: Turkic Languages ed. Lars Johanson, s. 239-252.

Şçerbak, A.M. (1961). Nazvaniya domaşnih i dikih jivotnıh v tyurkskih yazıkah. Moskva: İstoriçeskoe razvitye leksiki tyurkskih yazıkov.

Sevortyan, E. V. (1974, 1978, 1980). Etimologiçeskiy Slovar’'Tyurkskih Yazıkov. Moskva.

Seydakmatov, K. (1988). Kırgız Tilinin Kıskaça Etimmologiyalık Sözdügü. Frunze: Kırgız İlimder Akademiyasi.

Shawn, R.B. (2014). Kâşgar ve Yarkend A ğzı Sözlüğü. Çev. Fikret Yıldırım. Ankara: Türk Dil Kurumu. Sir Clauson, G. (1972). An Etymological Dictionary of Pre-Thirteenth-Century Turkish. Oxford.

Türk Dil Kurumu (2009). Derleme Sözlüğ̈̈ 3. Bask1. Ankara.

Türk Dil Kurumu (2011). Türkçe Sözlük. 11. Bask1. Ankara.

Yudahin, K. K. (1965). Kirgizsko-Russkiy Slovar’ I-II. Moskva: Sovetskya Ensklopediya.

\section{Kisaltmalar}

Alt: Altay Türkçesi

Ar: Arabça

Çağ: Çağatay Türkçesi

DLT: bak. Ercilasun, Akkoyunlu

DS: Derleme Sözlüğü

ET: Eski Türkçe

EUD: bk. Ayazlı

Far. Farsça

Fr: Fransizca

GK: Güney Kırgızistan

Hak: Hakas Türkçesi

İRL TJa: bk. Şçerbak 
KalmRS: Kalmukça Rusça Sözlüğü

KazRS: Kazakça Rusça Sözlük

KazTS: Kazakça Türkçe Sözlük

KK: Kuzey Kırgızistan

Koib. Koybalice

KWb: bk. Ramstedt

Leb: Lebed (Kuu-Kiji)

Moğ: Moğolca

MoğRS: Moğolca Rusça Sözlük

OsmTürS: Osmanlı Türkçesi Sözlüğü

OT: Orta Türkçe

ÖzbRS: Özbekçe Rusça Sözlük

Rus: Rusça

RSAlt: Rusça Altayca Sözlük

Sag: Sagayca

Tel: Teleut

TMEN: bk. Doerfer

Tuv: Tuva Türkçesi

TTür. Türkiye Türkçesi

Y.UygRS: Yeni Uygur Rusça Sözlük

Y.UygTS: Yeni Uygur Türkçe Sözlük 
